\title{
Are obese rats influenced by GLP1 and IR through aerobic exercise? A case study
}

\author{
Ali SAYYAH ${ }^{1}$, Hamid MOHEBBI ${ }^{1}$, Hamid ARAZI ${ }^{1}$, Abbas BAHARI ${ }^{2}$ \\ ${ }^{1}$ Department of Exercise Physiology, Faculty of physical education $\mathcal{E}$ Sport Sciences, University of Guilan, Rasht, Iran. \\ 2 Biotechnology Group, Research Institute of Modern Biological Techniques, University of Zanjan, Iran. \\ Address correspondence to A. Sayyah, alisayyah1899@gmail.com
}

\begin{abstract}
The present study aimed to consider the influence of aerobic exercise intensity on GLP-1and IR in obese rats. Glucagon-like peptide1 (GLP-1) is characterized as incretion hormones secreted from the intestine upon ingestion of food to maximize insulin secretion, regulate blood sugar and enhance insulin resistance (IR). It was an in vitro study. The study subjects were thirty-two male Wistar rats which were divided into 4 groups: three levels of aerobic training intensity (high, moderate and low intensity) and one control group. Following 8 weeks of different intensity of aerobic trainings, the researchers calculated plasma concentration of glucose, insulin, HOMA-IR and GLP-1. We applied dependent t-test and Analysis of variance (ANOVA) to test the research hypotheses. Body weight, BMI, insulin, blood glucose and HOMA-IR in high, moderate and low intensity of aerobic training were noticed to be significantly lower than in the control group $(\mathrm{P}=0.001)$ following an eight-week intervention. However, moderate and high intensity of aerobic training compared with low intensity significantly showed a decrease in insulin, blood glucose, HOMA-IR, and GLP-1. The findings revealed that moderate and high intensity of aerobic training results in GLP-1 secretion impairment, thus its improvement can cause a reduction in insulin resistance and blood glucose regulation.
\end{abstract}

Keywords: Aerobic exercise, glucagon-like peptide-1, insulin resistance

\section{INTRODUCTION}

The overweight and obesity is the result of imbalance between energy intake and energy consumption. The increased energy intake, insufficient physical activity, and sedentary lifestyle may lead to obesity $(32,40)$. The reduction of calorie intake and increase of daily energy consumption through physical activity are effective ways to deal with this situation (39). The exercise may directly increase energy consumption and change involved hormones secretion to impact on energy intake and energy consumption in physical activity. Obviously, the exercise-induced weight loss also depends on its compensation effect on food intake. If an activity increase energy intake as energy consumption, its effect on weight loss will disappear (39). There are many researches on activities and their impact on increase of fat burn; however, there are less data on energy intake. One of the reasons for less research on this area is that it is difficult to accurately measure energy intake. For this reason, most studies are about the acute effects of active $(3,9)$. These studies show that the activities with different intensities have different effects on appetite, energy intake, and energy regulating hormones. For example, many studies show that high activity reduces hunger feeling, with no change in energy intake $(21,40)$. Some studies have shown that high intensity activity increases energy intake $(23,34)$ while, some other studies show that it reduces energy intake $(44,45)$. The low and moderate-intensity activity does not cause changes in appetite and energy intake $(30,34)$.

On the other hand, the consumption of high-fat and high-carbohydrate meal is the most important physiological stimulant of glucagon-like peptide receptors (GLP-1) 1 (46). The GLP-1 is from Incretin family; it is a gastrointestinal hormone which is secreted in response to glucose consumption by 
intestinal cells and plays an important role in glucose homeostasis (27). These hormones are responsible for secretion of 50 to $70 \%$ insulin which is secreted after oral glucose intake (6). They also may conduct this activity after eating food and before the rise of blood glucose level (2). The GLP-1 release may be stimulated by combined meals or specific nutrients such as glucose and other sugars, fatty acids, essential amino acids, and fiber diet. This hormone is the strongest known incretin in human and the manipulation of it system may lead to creation of important and new therapeutic methods for treatment of type-2 diabetes. Since the removal of GLP-1 is similar in healthy people, obese people, and people with type-2 diabetes, the decreased level of GLP-1 in obese people and people with type 2 diabetes is probably due to decreased secretion of GLP-1 peptide (2). Although leptin may stimulate the secretion of GLP-1, the obese people often show leptin resistance. Therefore, it has been suggested that leptin resistance may be responsible for reducing levels of GLP-1 in obese women (4). There is very little information about the effect of exercise on GLP-1.This is important, because exercise is the first step for prevention and treatment of type 2 diabetes (14, 15). One hour cycling at $65 \%$ maximum heart rate shows a significant increase in plasma levels GLP-1 and leads to reduced hunger in young men and women with normal body weight (1). The GLP-1 level in healthy young men is similar in high-intensity exercise $(75 \%$ of maximum oxygen consumption) and moderate level exercise $(50 \%$ of maximum oxygen consumption) (11). These results suggest that the exercise may partly act as a physiological regulator for metabolism or release of GLP-1 and thus lead to appetite control. The research shows the intensity of exercise which may change blood levels of these variables and insulin resistance index $(19,24)$. Naturally, the energy consumption in high intensity exercise is higher than moderate and low exercises; if energy consumption will be higher, the reduction of fat mass will be considered. Among the variables affecting GLP-1, the body weight and insulin resistance index are important factors; these factors are especially significant with an increase in fat mass. Accordingly, this question is raised: whether positive changes in blood levels GLP-1 and insulin resistance index can be expected by weight loss. Finally, according to research results, the impact of different intensities of physical activity on plasma levels GLP-1 and insulin resistance index is still not fully understood. Therefore, it seems necessary to investigate the effects of different exercise intensities considering training volume to provide an appropriate exercise program to promote health and prevent from metabolic disorders like insulin resistance. However, this study aims to investigate the effect of 8 weeks aerobic training with three different (high, medium, and low) intensities on plasma levels of GLP-1 and insulin resistance index in obese rats.

\section{METHODS \& MATERIALS}

\section{Subjects}

A total of 32 male Wistar rats (age $=5$-month, weight range $=320-350$ grams) were taken from Laboratory Animals Cultivation and Breeding Centre, Pasteur Institute of Iran. At all test stages, these animals were kept under controlled and accurate conditions in terms of diet, ambient temperature (21 \pm $\left.3^{\circ} \mathrm{C}\right)$, humidity (50 \pm 5 percent), stress and light (12 hours darkness and 12 hours daylight) in groups of four. In all stages of research, these animals had enough and free access to rat foods and drinking water. As targeted and based on body weight, these animals were randomly divided into 4 groups of 8 including high-intensity aerobic exercise group, moderate-intensity aerobic exercise group, lowintensity aerobic exercise group, and control group.

\section{Exercise Protocol}

The exercise program included 5 sessions of aerobic exercise per week; it was conducted for 8 weeks on rodents' treadmill. Each session included warm-up, workout, and cool down. At this stage, the exercise group exercised five times a week; the control group was kept without any activity in the cage. The running duration at moderate and high exercise groups was obtained based on following formula; therefore, the duration of running was same in all 3 groups:

$$
\text { Speed }=\text { Distance } \div \text { Time }
$$

In order to adapt rats with running on rodent treadmill, the exercise duration in each session in 2 first weeks was 10 to 15 minutes at a speed of $10-12$ meters per minute with a slope of zero percent. In the next 6 weeks (overload stage), the non-linear loading model was used to increase the training load (overload principle); during this time, gradually, the 
exercise intensity of rats in high, moderate, and low intensity exercise groups was increased to 85\% (34 meters per minute, slope of zero percent), 75\% (28 meters per minute, slope of zero percent), and 55\% (20 meters per minute, slope of zero percent) of maximum oxygen consumption, respectively (exercise volume = 1,200 meters per session). To cool down at the end of each training session, the speed of treadmill reduced reversely to initial speed. In order to eliminate potential stress levels among animals, the control group also ran for 5 minutes once a week at speed of 12 meters per minute with a slope of zero percent.

\section{Data collection method}

In the present study, considering the weight of subjects, the daily food intake was determined once a week. Then, the amount of food residue was remeasured and was deducted from initial amount. The amount of daily food intake of rats was measured with a digital scale with a precision of 0.1 gram. At the same time measuring food intake amount, the weight of each rat was measured to evaluate the weight changes in rats once a week. The height of these animals was measured in a state of complete anesthesia from tip of their nose to their anus in pretest and post-test. The Body Mass Index was determined using this formula: weight (grams) divided by square of height $(\mathrm{cm})$. After the end of last week and after 12 hours of fasting, the blood samples were directly taken from heart. Then, the blood samples were poured in tubes containing EDTA
(Ethylene-diamineteraacetic acid). To separate blood plasma, the samples were kept for $15 \mathrm{~min}$ at $4^{\circ} \mathrm{C}$ at $3000 \mathrm{rpm}$ centrifuge and a temperature of $80^{\circ} \mathrm{C}$. The GLP-1, fasting blood glucose, and insulin levels were measured using ELISA method (MyBioSource kit, America), enzymatic method (kit of ParsAzmoon, Iran), and ELISA method (Zellbio kit, Germany), respectively. The insulin resistance was calculated using HOMA-IR index by following equation (16).

Insulin Resistance Index= Insulin (micro unit per deciliter $) \times$ [glucose (milligrams per milliliter)/ 22.5]

\section{Statistical Methods}

The paired t-test was used to compare the mean of body weight, body mass index, and food intake in pre-test and post-test; also, One-way analysis of variance (ANOVA) was used to compare the mean of body weight, BMI, food intake, and insulin resistance among groups. In the case of significance, Tukey's test was conducted in SPSS version 22 at a significance level of $\mathrm{P}<0.05$.

\section{RESULTS}

According to ANOVA test results, Table 1 shows the body weight, height, and body mass index of groups in pre-test and post-test. According to ANOVA test results in Table 1, there was no significant difference in body weight, height, and body mass index of groups in pre-test; while, there was significant difference in body weight and body mass index of groups in post-test.

Table 1. Mean of body weight, height, and body mass index of different groups throughout the study.

\begin{tabular}{|c|c|c|c|c|c|c|}
\hline \multirow[b]{2}{*}{ Variables } & & \multicolumn{4}{|c|}{ Groups } & \multirow[b]{2}{*}{ P Value } \\
\hline & & $\begin{array}{l}\text { Exercise with } \\
\text { high intensity }\end{array}$ & $\begin{array}{c}\text { Exercise with } \\
\text { moderate intensity }\end{array}$ & $\begin{array}{l}\text { Exercise with } \\
\text { low intensity }\end{array}$ & Control & \\
\hline \multirow{4}{*}{ Weight(kg) } & Pre-test & $21.96 \pm 340.06$ & $20.70 \pm 345.44$ & $26.15 \pm 340.05$ & $37.55 \pm 342.97$ & 0.763 \\
\hline & Post-test & $24.86 \pm 320.25 \dagger$ & $31.83 \pm 313.05 \dagger$ & $30.89 \pm 333.33$ & $30.97 \pm 363.03$ & $0.001 *$ \\
\hline & P Value & $0.032 ¥$ & $0.021 ¥$ & 0.072 & $0.031 ¥$ & \\
\hline & Pre-test & $0.03 \pm 23.30$ & $0.05 \pm 23.50$ & $0.03 \pm 23.18$ & $0.06 \pm 23.09$ & 0.912 \\
\hline \multirow{2}{*}{ Height (cm) } & Post-test & $0.03 \pm 23.40$ & $0.07 \pm 23.55$ & $0.03 \pm 23.25$ & $0.06 \pm 23.19$ & 0.763 \\
\hline & P Value & 0.087 & 0.092 & 0.085 & 0.063 & \\
\hline \multirow{3}{*}{ BMI $\left(\mathrm{g} / \mathrm{cm}^{2}\right)$} & Pre-test & $0.003 \pm 0.62$ & $0.002 \pm 0.62$ & $0.001 \pm 0.63$ & $0.004 \pm 0.64$ & 0.053 \\
\hline & Post-test & $0.002 \pm 0.58 \dagger$ & $0.004 \pm 0.56 \dagger$ & $0.002 \pm 0.61$ & $0.09 \pm 0.67$ & $0.001 *$ \\
\hline & P Value & $0.028 ¥$ & $0.011 ¥$ & 0.066 & $0.033 ¥$ & \\
\hline
\end{tabular}

t: Significant difference between high and moderate intensity aerobics exercise groups and low intensity aerobic exercise group and control group; ¥: Significant difference between pre-test and post-test; ${ }^{*}$ : Significant difference between groups; significance level is $\mathrm{P}<0.05$ 
Table 2. Mean of insulin, glucose, and insulin resistance index of different groups.

\begin{tabular}{|c|c|c|c|c|c|}
\hline \multirow[b]{2}{*}{ Variables } & \multicolumn{4}{|c|}{ Groups } & \multirow[b]{2}{*}{ P Value } \\
\hline & $\begin{array}{l}\text { Exercise withhigh } \\
\text { intensity }\end{array}$ & $\begin{array}{c}\text { Exercise with } \\
\text { moderate intensity }\end{array}$ & $\begin{array}{l}\text { Exercise with } \\
\text { low intensity }\end{array}$ & Control & \\
\hline $\operatorname{Insulin}(\mu \mathrm{g} / \mathrm{L})$ & $0.035 \pm 0.01 \dagger$ & $0.028 \pm 0.002 \dagger$ & $0.073 \pm 0.054$ & $0.086 \pm 0.042$ & 0.001 * \\
\hline Glucose $(\mathrm{mg} / \mathrm{dL})$ & $149.33 \pm 36.11 \dagger$ & $158.16 \pm 31.55 \dagger$ & $188 / 50 \pm 16 / 4$ & $170.33 \pm 17.07$ & 0.001 * \\
\hline HOMA-IR & $0.55 \pm 0.32 \dagger$ & $0.41 \pm 30.05 \dagger$ & $1.94 \pm 1.76$ & $0 \pm 1.03$ & 0.001 * \\
\hline
\end{tabular}

t: Significant difference between high and moderate intensity aerobics exercise groups and low intensity aerobic exercise group and control group; *: Significant difference between groups; significance level is $\mathrm{P}<0.05$

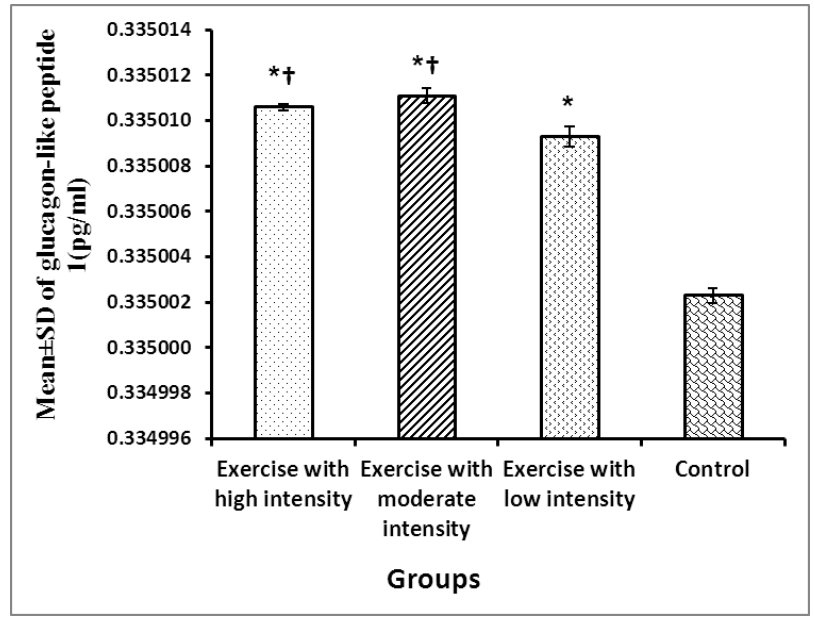

Figure 1. GLP-1 means values of groups.

Also, the paired t-test results in Table 1 show that the mean of weight and body mass index in pre-test and post-test of high-intensity and moderate-intensity aerobic exercise groups decreased significantly; it also decreased in low-intensity aerobic exercise group, but it was not statistically significant. In control group, however, the mean of body weight and body mass index in increased significantly in post-test compared to pre-test $(\mathrm{P}<0.01)$.

According to ANOVA test results, Table 2 shows the insulin level, glucose level, and insulin resistance index of groups. According to Table 2, there is a significant difference in insulin level, glucose level, and insulin resistance index. According to Tukey test, there is significant difference in insulin level, glucose level, and insulin resistance index of high and moderate intensity aerobic exercise groups and lowintensity aerobic exercise group and control group.

According to ANOVA test results in Figure 1, there is significant difference in plasma levels of GLP1. According to Tukey post-hoc test, there is significant difference in plasma levels of GLP-1 in high and moderate intensity exercise groups and low intensity aerobic exercise groups and control group.

\section{DISCUSSION}

This study aimed to investigate the effect of aerobic exercise at different (high, medium, low) intensities on insulin resistance index and plasma levels of GLP-1 in obese rats. The findings showed that the high-intensity and moderate-intensity aerobic exercise led to a significant decrease in body weight and body mass index. The statistical analysis showed that there is significant difference between groups in these three variables; therefore, this finding is consistent with results of some studies $(14,33)$. The findings of Pilegaard et al. (33) was consistent with findings of this study; however, since Pilegaard et al. did not control exercise energy consumption in two groups, the reduction of body fat percentage in the high intensity exercise group was attributed to higher energy consumption rather than exercise intensity. Slentz et al. (36) and Mougios et al. (31) found that there was no significant difference between groups in terms of impact of exercise intensity on body mass, 
but the weight loss occurred more in low intensity exercise group; this is inconsistent with the findings of this study. The lower body mass reduction in high intensity exercise groups in the study of Slentz et al. (36) and Mougios et al. (31) can be explained by increase of lean body mass in these studies. Mougios et al. (31) stated that the high reduction of body weight in low intensity exercise group compared to high intensity exercise group is due to their different effects on nutritional habits and physical activities.

Also, the findings showed that the insulin level, fasting blood glucose level, and insulin resistance level decreases in moderate and high-intensity aerobic exercise groups. This is consistent with the study of Hagobian et al. (17) who showed that the high intensity exercise decreases insulin concentration in both obese men and obese women. However, Humard et al. (22) showed that the 7 days of activity did not cause significant change in insulin concentration, but it improved insulin sensitivity in young and older men. The present study showed significant difference between high and moderate intensity aerobic exercise groups and low intensity aerobic exercise group and control group.On the other hand, it showed that the moderate and high intensity aerobic exercise decreased significantly the body weight and body mass index compared with low-intensity aerobic exercise.Although the findings of three levels of activity are different,it seems that the reduction of calorie intake, lose weight, and body mass index is due to these changes. Given that obesity and sedentary lifestyle are the key factors in development of insulin resistance, the weight loss may improve insulin resistance. Stubbs et al. (38) studied women and showed those 7 days of activity increases feeling of hunger in both high and low intensity activity. However, Hagubian et al. (16) showed no changes in appetite of obese women after 4 days of activity. Some studies have suggested that only high intensity exercise (greater than or equal to $70 \%$ of maximum oxygen uptake) may reduce insulin resistance index $(5,43)$. While, other studies have shown that insulin resistance index can also be improved by low and moderate physical activity $(22,25)$. It is possible that the low intensity aerobic exercise will not be able to create change in insulin resistance index. Totally, the difference in results may be due to several factors such as the amount of fat and its distribution, inflammatory conditions, kidney function, hormones, and other numerous factors. Also, some of the differences may be due to differences in hormone test business kits.

In the present study, the plasma levels of GLP-1 increased significantly after moderate and highintensity activity; while, low-intensity activity caused no significant change compared with control group. However, there is limited information about the effects of different intensities of aerobic exercise on plasma levels of GLP-1 in obese rats. Martins et al. (29) studied the effects of exercise on peptides of stomach, absorbing energy and appetite and concluded that one hour cycling exercise at $65 \%$ of maximum heart rate significantly increased plasma levels of GLP-1 and subsequently, reduced hungerrelated scores in normal-weight young men and women. Also, Ueda et al. (42) showed that one period of aerobic exercise significantly increased plasma levels of GLP-1 and decreased absorption of energy in obese and non-obese subjects. In addition, the increase of GLP-1 level during exercise was associated significantly and negatively with reduction of absorbed energy level. Also, the GLP-1 level in high $(75 \%$ of maximum oxygen consumption) and moderate ( $50 \%$ of maximum oxygen consumption) intensity exercise groups was similar in healthy male subjects.

According to research results, the plasma levels of GLP-1 impact directly and indirectly on increase of insulin and decrease of blood glucose $(18,35)$. On the one hand, it directly increases insulin gene expression and its synthesis through receptors on pancreas cells $(28,41)$. On the other hand, it increases insulin secretion through direct effect on its own receptors on pancreatic $\beta$ cells $(20,26)$ and also indirectly through hepatic portal vein and vagus nerve system $(7,12)$. Based on the studies, GLP-1 enters portal circulation and activates a glucose sensor in portal vein. Through vagus afferent nerves, this sensor sends signals to pancreas which causes insulin secretion from pancreas $(8,12)$. It also has a direct effect on pancreatic $\alpha$ cells which reduces release and secretion of glucagon (8). On the other hand, it reduces gastric emptying speed, leads to slow absorption of glucose, avoids sudden increase of blood glucose (10), and reduces food intake (37). This study showed that the moderate and high intensity aerobic exercise may increase plasma levels of GLP-1; the increase of GLP-1 level also increased insulin secretion during exercise 
and ultimately reduced insulin resistance. On the other hand, the low intensity aerobic exercise reduced GLP-1 level and increased insulin resistance and weight loss compared with medium and high intensity aerobic exercise .Due to lack of studies, the relationship between GLP-1 changes and insulin resistance in response to exercise intensity is not yet known. In general, however, considering the lack of significant effect of low-intensity activity on insulin resistance index and GLP-1, the lack of significant changes in body weight and body mass index is not unexpected. The findings showed that in the case of same food intake, there is difference between low, medium, and high intensity exercise groups.Also, considering the high ability of both medium and high intensity exercise compared to low intensity exercise in creation of negative energy balance, it seems that moderate intensity exercise is enough for weight loss. Although, there is a need for further investigations in this field to achieve an overall model, according to findings of this study, it can be recommended for obese people to control their exercise, diet, and exercise intensity to ensure weight loss.

\section{REFERENCES}

1. Abdul-Ghani MA, Matsuda M, Balas B, DeFronzo RA. Muscle and liver insulin resistance indexes derived from the oral glucose tolerance test. Diabetes Care, 2007; 30(1): 89-94.

2. Amori RE, Lau J, Pittas AG. Efficacy and safety of incretin therapy in type 2 diabetes: systematic review and metaanalysis. Jama, 2007; 298(2): 194-206.

3. Balaguera-Cortes L, Wallman KE, Fairchild TJ, Guelfi KJ. Energy intake and appetite-related hormones following acute aerobic and resistance exercise. Applied Physiology, Nutrition, and Metabolism, 2011; 36(6): 958-966.

4. Boschmann M, Engeli S, Dobberstein K, Budziarek P, Strauss A, Boehnke J, et al. Dipeptidyl-peptidase-IV inhibition augments postprandial lipid mobilization and oxidation in type 2 diabetic patients. The Journal of Clinical Endocrinology \& Metabolism, 2009; 94(3): 846-852.

5. Bozinovski NC, Bellissimo N, Thomas SG, Pencharz PB, Goode $\mathrm{RC}$, Anderson GH. The effect of duration of exercise at the ventilation threshold on subjective appetite and short-term food intake in 9 to 14 year old boys and girls. International Journal of Behavioral Nutrition and Physical Activity, 2009; 6(1): 1 .

6. Brown J, Dryburgh J, Ross S, Dupre J. Identification and actions of gastric inhibitory polypeptide. Recent Progress in Hormone Research, 1974; 31: 487-532.

7. Buchwald H, Dorman RB, Rasmus NF, Michalek VN, Landvik NM, Ikramuddin S. Effects on GLP-1, PYY, and leptin by direct stimulation of terminal ileum and cecum in humans: implications for ileal transposition. Surgery for Obesity and Related Diseases, 2014; 10(5): 780-786.

8. Cegla J, Troke RC, Jones B, Tharakan G, Kenkre J, McCullough $\mathrm{KA}$, et al. Coinfusion of low-dose GLP-1 and glucagon in man results in a reduction in food intake. Diabetes, 2014; 63(11): 3711-3720.

9. Deighton K, Zahra JC, Stensel DJ. Appetite, energy intake and resting metabolic responses to $60 \mathrm{~min}$ treadmill running performed in a fasted versus a postprandial state. Appetite, 2012; 58(3): 946-954.

10. Delgado-Aros S, Kim D-Y, Burton DD, Thomforde GM, Stephens D, Brinkmann BH, et al. Effect of GLP-1 on gastric volume, emptying, maximum volume ingested, and postprandial symptoms in humans. American Journal of Physiology-Gastrointestinal and Liver Physiology, 2002; 282(3): G424-G31.

11. Drucker DJ. Dipeptidyl peptidase-4 inhibition and the treatment of type 2 diabetes preclinical biology and mechanisms of action. Diabetes Care. 2007; 30(6): 1335-1343.

12. Elahi D, Ruff DA, Carlson OD, Meneilly GS, Habener JF, Egan JM. Does GLP-1 suppress its own basal secretion? Endocrine Research, 2016; 41(1): 16-20.

13. Fadini GP, Avogaro A. Cardiovascular effects of DPP-4 inhibition: beyond GLP-1. Vascular Pharmacology, 2011; 55(1): 10-16.

14. Fernström M, Tonkonogi M, Sahlin K. Effects of acute and chronic endurance exercise on mitochondrial uncoupling in human skeletal muscle. The Journal of Physiology, 2004; 554(3): 755-763.

15. Grundy SM, Cleeman JI, Daniels SR, Donato KA, Eckel RH, Franklin BA, et al. Diagnosis and management of the metabolic syndrome an American Heart Association/National Heart, Lung, and Blood Institute scientific statement. Circulation, 2005; 112(17): 2735-2752.

16. Hagobian TA, Braun B. Physical activity and hormonal regulation of appetite: sex differences and weight control. Exercise and Sport Sciences Reviews, 2010; 38(1): 25-30.

17. Hagobian TA, Sharoff CG, Stephens BR, Wade GN, Silva JE, Chipkin SR, et al. Effects of exercise on energy-regulating hormones and appetite in men and women. American Journal of Physiology-Regulatory, Integrative and Comparative Physiology 2009; 296(2): R233-R42.

18. Heni M, Kullmann S, Gallwitz B, Häring H-U, Preissl H, Fritsche A. Dissociation of GLP-1 and insulin association with food processing in the brain: GLP-1 sensitivity despite insulin resistance in obese humans. Molecular Metabolism, 2015; 4(12): 971-976.

19. Herrmann C, Göke R, Richter G, Fehmann H-C, Arnold R, Göke B. Glucagon-like peptide-1 and glucose-dependent insulinreleasing polypeptide plasma levels in response to nutrients. Digestion, 1995; 56(2): 117-126.

20. Holst JJ, Gromada J. Role of incretin hormones in the regulation of insulin secretion in diabetic and nondiabetic humans. American Journal of Physiology-Endocrinology and Metabolism, 2004; 287(2): E199-E206. 
21. Horner KM, Schubert MM, Desbrow B, Byrne NM, King NA. Acute exercise and gastric emptying: a meta-analysis and implications for appetite control. Sports Medicine, 2015; 45(5): 659-678.

22. Houmard JA, Cox JH, MacLean PS, Barakat HA. Effect of shortterm exercise training on leptin and insulin action. Metabolism, 2000; 49(7): 858-861.

23. Howe SM, Hand TM, Larson-Meyer DE, Austin KJ, Alexander $\mathrm{BM}$, Manore MM. No effect of exercise intensity on appetite in highly-trained endurance women. Nutrients, 2016; 8(4): 223.

24. Idorn T, Knop FK, Jørgensen MB, Christensen M, Holst JJ, Hornum $\mathrm{M}$, et al. Elimination and degradation of glucagon-like peptide- 1 and glucose-dependent insulinotropic polypeptide in patients with end-stage renal disease. The Journal of Clinical Endocrinology \& Metabolism, 2014; 99(7): 2457-2466.

25. Kampmann U, Mosekilde L, Juhl C, Moller N, Christensen B, Rejnmark L, et al. Effects of 12weeks high dose vitamin D3 treatment on insulin sensitivity, beta cell function, and metabolic markers in patients with type 2 diabetes and vitamin D insufficiency-a double-blind, randomized, placebo-controlled trial. Metabolism, 2014; 63(9): 1115-1124.

26. Knop FK, Lund A, Madsbad S, Holst JJ, Krarup T, Vilsbøll T. Unprecedented high insulin secretion in a healthy human subject after intravenous glucagon-like peptide-1: a case report. BMC Research Notes, 2014; 7(1): 1.

27. Lovshin JA, Drucker DJ. Incretin-based therapies for type 2 diabetes mellitus. Nature Reviews Endocrinology, 2009; 5(5): 262-269.

28. Maino B, Ciotti MT, Calissano P, Cavallaro S. Transcriptional analysis of apoptotic cerebellar granule neurons following rescue by gastric inhibitory polypeptide. International Journal of Molecular Sciences, 2014; 15(4): 5596-5622.

29. Martins C, Morgan LM, Bloom SR, Robertson MD. Effects of exercise on gut peptides, energy intake and appetite. Journal of Endocrinology, 2007; 193(2): 251-258.

30. Martins C, Stensvold D, Finlayson G, Holst J, Wisloff U, Kulseng $\mathrm{B}$, et al. Effect of moderate-and high-intensity acute exercise on appetite in obese individuals. Medicine \& Science in Sports \& Exercise, 2015; 47(1): 40-48.

31. Mougios V, Kazaki M, Christoulas K, Ziogas G, Petridou A. Does the intensity of an exercise programme modulate body composition changes? International Journal of Sports Medicine, 2006; 27(03): 178-181.

32. Ogden CL, Carroll MD, Kit BK, Flegal KM. Prevalence of childhood and adult obesity in the United States, 2011-2012. Jama, 2014; 311(8): 806-814.

33. Pilegaard H, Ordway GA, Saltin B, Neufer PD. Transcriptional regulation of gene expression in human skeletal muscle during recovery from exercise. American Journal of PhysiologyEndocrinology and Metabolism, 2000; 279(4): E806-E14.

34. Pomerleau M, Imbeault P, Parker T, Doucet E. Effects of exercise intensity on food intake and appetite in women. The American Journal of Clinical Nutrition, 2004; 80(5): 1230-1236.
35. Sjøberg KA, Rattigan S, Jeppesen JF, Lundsgaard AM, Holst JJ, Kiens B. Differential effects of glucagon-like peptide-1 on microvascular recruitment and glucose metabolism in shortand long-term insulin resistance. The Journal of Physiology, 2015; 593(9): 2185-2198.

36. Slentz CA, Duscha BD, Johnson JL, Ketchum K, Aiken LB, Samsa GP, et al. Effects of the amount of exercise on body weight, body composition, and measures of central obesity: Strride-a randomized controlled study. Archives of Internal Medicine, 2004; 164(1): 31-39.

37. Steinert RE, Schirra J, Meyer-Gerspach AC, Kienle P, Fischer H, Schulte F, et al. Effect of glucagon-like peptide-1 receptor antagonism on appetite and food intake in healthy men. The American Journal of Clinical Nutrition, 2014; 100(2): 14-23.

38. Stubbs RJ, Sepp A, Hughes DA, Johnstone AM, Horgan GW, King NA, et al. The effect of graded levels of exercise on energy intake and balance in free-living men, consuming their normal diet. European Journal of Clinical Nutrition, 2002; 56: 129-140.

39. Symons Downs D, Evenson KR, Chasan-Taber L, editors. Obesity and physical activity during pregnancy and postpartum. Springer-Verlag London Ltd; 2014.

40. Thompson DA, Wolfe LA, Eikelboom R. Acute effects of exercise intensity on appetite in young men. Medicine and Science in Sports and Exercise, 1988; 20(3): 222-227.

41. Tsukiyama K, Yamada Y, Yamada C, Harada N, Kawasaki Y, Ogura $\mathrm{M}$, et al. Gastric inhibitory polypeptide as an endogenous factor promoting new bone formation after food ingestion. Molecular Endocrinology, 2006; 20(7): 1644-1651.

42. Ueda S-y, Yoshikawa T, Katsura Y, Usui T, Nakao H, Fujimoto $\mathrm{S}$. Changes in gut hormone levels and negative energy 42 balance during aerobic exercise in obese young males. Journal of Endocrinology, 2009; 201(1): 151-159.

43. Van Engelen M, Khodabandeh S, Akhavan T, Agarwal J, Gladanac B, Bellissimo N. Effect of sugars in solutions on subjective appetite and short-term food intake in 9-to 14-yearold normal weight boys. European Journal of Clinical Nutrition, 2014; 68(7): 773-777.

44. Verger P, Lanteaume M, Louis-Sylvestre J. Free food choice after acute exercise in men. Appetite, 1994; 22(2): 159-164.

45. Westerterp-Plantenga MS, Verwegen CR, IJedema MJ, Wijckmans NE, Saris WH. Acute effects of exercise or sauna on appetite in obese and nonobese men. Physiology \& Behavior, 1997; 62(6): 1345-1354.

46. Yazbeck R. Teduglutide, a glucagon-like peptide-2 analog for the treatment of gastrointestinal diseases, including short bowel syndrome. Current Opinion in Molecular Therapeutics, 2010; 12(6): 798-809. 